\title{
A DITADURA MILITAR NARRADA NOS LIVROS DIDÁTICOS DE HISTÓRIA
}

\author{
MILITARY DICTATORSHIP NARRATED IN THE HISTORY TEXTBOOKS
}

Osvaldo Rodrigues Junior ${ }^{1}$

Leticia Seba

\begin{abstract}
Resumo: Apresenta resultados parciais de pesquisa em desenvolvimento no Programa de Iniciação Científica - PIBIC da Universidade Federal de Mato Grosso UFMT, que tem como objetivo analisar as narrativas históricas acerca do golpe e da Ditadura Militar no Brasil nos livros didáticos de História aprovados pelo Programa Nacional do Livro Didático - PNLD. Os objetivos específicos do trabalho foram: a) Realizar uma revisão bibliográfica acerca do golpe e da Ditadura Militar no Brasil; b) Inventariar os livros didáticos de História para o Ensino Fundamental aprovados pelo PNLD; c) Analisar três livros didáticos de História da aprovados pelo PNLD 2017. Foram analisadas as coleções História, Sociedade \& Cidadania (2015), Araribá - História (2015) e Vontade de Saber (2015). Na análise assumimos como referencial teórico-metodológico o modelo de crítica científica da interpretação histórica presente nos livros didáticos e as tipologias de narrativas históricas propostos por Rüsen (2010). O modelo de crítica é sustentando em um conjunto de critérios para análise do livro didático. Optamos pela análise dos critérios de apresentação dos materiais históricos (textos), pluralidade da experiência histórica, pluriperspectividade e normas científicas por considerá-los essenciais para 0 desenvolvimento narrativo do livro didático. Assim procuramos identificar a presença das tipologias de narrativa histórica: tradicional (afirmação), exemplar (regularidade), crítica (negação) e genética (transformação). Os resultados parciais nos permitiram observar a ausência de textos historiográficos na apresentação dos materiais históricos. A predominância da política como âmbito de experiência e a inexistência das várias perspectivas da história. Contudo, há uma razoável adoção das normas científicas no que diz respeito a historiografia. Entendemos que a ausência dos critérios analisados está intimamente relacionada ao predomínio da narrativa histórica tradicional presente no livro didático analisado.
\end{abstract}

Palavras-chave: Ditadura militar; Livros didáticos; Narrativa histórica.

\footnotetext{
1 Doutor em Educação. Professor Adjunto do Departamento de História da Universidade Federal de Mato Grosso. Professor permanente do Programa de Pós-Graduação em História e Mestrado Profissional em Ensino de História da Universidade Federal de Mato Grosso. Membro do Núcleo de Pesquisas em Publicações Didáticas da Universidade Federal do Paraná. Email: osvaldo.rjunior@gmail.com.

2 Acadêmica do curso de Licenciatura em História da Universidade Federal de Mato Grosso. Bolsista de Iniciação Científica do Conselho Nacional de Desenvolvimento Científico e Tecnológico - CNPQ. Email: leticiasebacdoc@gmail.com.
} 
ABSTRACT: This text presents partial results of the research in development on the Program of Scientific Initiation - PIBIC of the Federal University of Mato Grosso - UFMT, whose objective is to analyze the historical narratives about the coup and the Military Dictatorship in Brazil in the History textbooks approved by the National Program of Didactic Book - PNLD. The specific objectives of this work were: a) To carry out a bibliographic review about the coup and the Military Dictatorship in Brazil; b) To inventory the History textbooks for Elementary School approved by PNLD; c) Analyze three History textbooks approved by PNLD 2017. The collections History, Society \& Citizenship (2015), Araribá - História (2015) and Will to Know (2015) were analyzed. In the analysis, we assumed as theoretical-methodological reference the model of scientific criticism of the historical interpretation presented in textbooks and the typologies of historical narratives proposed by Rüsen (2010). The critique model is based on a set of criteria for the analysis of the textbook. We chose to analyze the criteria of presentation of historical materials (texts), plurality of historical experience, pluriperspectivity and scientific norms as essential for the narrative development of textbooks. Thus, we tried to identify the presence of the typologies of historical narrative: traditional (affirmation), exemplar (regularity), criticism (negation) and genetics (transformation). Partial results allowed us to observe the absence of historiographical texts in the presentation of historical materials. The predominance of politics as the scope of experience and the inexistence of the various perspectives of history. However, there is a reasonable adoption of scientific norms as far as historiography is concerned. We understand that the absence of the analyzed criteria is closely related to the predominance of the traditional historical narrative present in the textbook analyzed.

Keywords: Military Dictatorship - Textbooks - Historical narrative.

\section{Novos documentos e antigos problemas: os embates entre a memória e a História da Ditadura Civil-Militar no Brasil}

No ano de 2018 foi descoberto pelo pesquisador Mathias Spektor ${ }^{3}$ da Fundação Getúlio Vargas, um documento do ano de 1974, período em que o Brasil vivia a Ditadura Militar. No documento o general Milton Tavares de Souza, do Centro de Inteligência do Exército - CIE, envia uma carta a cúpula do governo de Ernesto Geisel alertando que o Brasil não poderia ignorar a "ameaça terrorista e subversiva", e que os métodos extralegais deveriam continuar a serem empregados contra subversivos. O grupo informava a Geisel da execução sumária de 104 pessoas no CIE durante o

\footnotetext{
3 Prof. Matias Spektor circula documento da CIA sobre o governo Geisel. Ver mais em: https://ri.fgv.br/noticias/2018-05-16/prof-matias-spektor-circula-documento-da-cia-sobreo-governo -geisel.
}

História \& Ensino, Londrina, v. 25, n. 02, p. 217-237, jul./dez. 2019 
governo Médici, e pedia autorização para continuar a política de assassinatos no novo governo. Em outro documento o presidente Geisel autoriza a manutenção dos métodos extralegais, no entanto alertava para "tomar muito cuidado para assegurar que apenas subversivos perigosos fossem executados", e que o CIE não mataria a esmo.

Apesar do jornalista Elio Gaspari (2003), em seu livro A Ditadura derrotada, ter apresentado diversos fatos que incriminam Geisel e os chefes militares da época com a tortura e o assassinato de presos, para o historiador Matias Spektor o documento é a evidência mais direta do envolvimento da cúpula do regime militar com a política de assassinatos durante a Ditadura.

Diante da divulgação do documento, mais uma vez vieram à tona os embates entre a memória e a história da Ditadura Militar, que tem pautado a vida política do Brasil.

Segundo Carlos Fico (2017), a abordagem historiográfica acerca da Ditadura Civil-Militar é algo recente, já que antes eram quase que restritas aos cientistas políticos, sociólogos ou narradas pelos próprios participes. Fico (2017) defende que um dos gêneros predominantes no que poderia ser caracterizado como primeira fase dos estudos sobre o período foi a memorialística, que cresceu sobretudo a partir da distensão política patrocinada pelo governo de Ernesto Geisel.

Os historiadores marxistas caracterizam o golpe de 64 como um ataque da classe dominante ao proletariado e por isso, "um episódio da luta de classes". Não há dúvidas, como o historiador Carlos Fico (2017) ressalta, que o golpe foi também um "movimento que objetivava garantir e aprofundar a inserção do Brasil no capitalismo" (FICO, 2017, p. 35). Daniel Aarão Reis (2014), por sua vez, afirma que o golpe e a ditadura receberam apoio de importantes setores da sociedade, enquanto Marcelo Badaró Mattos (2014) acredita que o golpe e a ditadura foram vitórias da burguesia. 
A tensão entre memória e História se apresenta também na crítica marxista aos revisionistas, responsáveis por fragilizar a esquerda e alimentar o discurso da direita (FICO, 2017, p. 36).

Daniel Aarão Reis (2014) traz a ideia de deslocamento de sentido, que se trata da memória confortável. Essa memória perpassa a definição de partes da esquerda como democráticas, quando o objetivo era implantar a "ditadura do proletariado" e pela preferência da sociedade brasileira pelo silêncio como memória (REIS, 2014, p. 136).

Segundo Fico (2017), o ponto principal seria a história da Ditadura Militar sendo vista como a história do confronto entre a repressão política e a "luta armada". O autor afirma que,

[...] ainda que tenham tido consequências dramáticas para os envolvidos e para o próprio processo de saída da ditadura - como ainda veremos -, as ações armadas foram poucas e sua fase verdadeiramente ofensiva ou revolucionária muitíssimo breve porque, diante da óbvia superioridade e truculência da repressão, elas se tornaram meramente defensiva (FICO, 2017, p.41).

Por outro lado, setores ligados à Ditadura Militar ainda hoje sustentam versões que não condizem com os documentos. Omitem informações, rechaçam evidências e falsificam o passado desconsiderando 0 conhecimento científico acumulado.

Sendo assim, podemos afirmar que a historiografia não permite um consenso sobre o golpe militar de 1964 e a Ditadura Civil-Militar, contudo a vasta documentação permite rejeitar a ideia de "Revolução" ou "democracia relativa" defendida por setores das Forças Armadas.

Partindo desse embate entre memória e História, o presente artigo tem como objetivo analisar as narrativas históricas acerca do golpe e da Ditadura Militar no Brasil nos livros didáticos de História do Ensino Fundamental aprovados pelo Programa Nacional do Livro Didático - PNLD 2017. Os objetivos específicos do trabalho foram: a) realizar um breve "estado da arte" das pesquisas que tratam da Ditadura Militar nos livros didáticos de História; b) inventariar os livros didáticos de História para os 
anos finais do Ensino Fundamental aprovados pelo PNLD 2017; c) analisar os três livros didáticos de História mais escolhidos pelos professores.

$\mathrm{Na}$ análise assumimos como referencial teórico-metodológico o modelo de crítica científica da interpretação histórica presente nos livros didáticos e as tipologias de narrativas históricas propostos por Rüsen (2010). O modelo de crítica é sustentando em um conjunto de critérios para análise do livro didático. Optamos pela análise dos critérios de apresentação dos materiais históricos (textos), pluralidade da experiência histórica, pluriperspectividade e normas científicas por considerá-los essenciais para o desenvolvimento narrativo do livro didático. Assim procuramos identificar a presença das tipologias de narrativa histórica: tradicional (afirmação), exemplar (regularidade), crítica (negação) e genética (transformação).

Para isso, o artigo está estruturado em três partes. A primeira em que discutimos os trabalhos sobre a Ditadura Militar nos livros didáticos de História. Na sequência, apresentamos os livros didáticos analisados. Por fim, indicamos os resultados obtidos nas análises.

\section{Um breve "estado da arte": a Ditadura Civil-Militar nos livros didáticos de História}

Sem a pretensão ingênua de incluirmos todos os trabalhos que tratam da temática nos livros didáticos de História, pretendemos realizar um breve "estado da arte" dos trabalhos que tratam da Ditadura Militar nos livros didáticos de História. Para isso, tomamos um conjunto de trabalhos, na sua maioria artigos científicos, procurando compreender como as investigações anteriores nos ajudam a compreender a questão posta por este trabalho.

Um primeiro conjunto de trabalhos, toma como fonte privilegiada os livros didáticos produzidos no contexto da Ditadura Militar. Entendendo os livros didáticos produzidos no período enquanto transmissores da ideologia do governo ditatorial, Rocha (2008) e Gomes Neto et al. (2014) fazem uma crítica, observando que o seu conteúdo, textual e imagético tinha como 
objetivo disseminar uma "ideologia cívica" formando cidadãos obedientes e dóceis.

Sobre isso, Rocha (2008) observa que:

[...] eram elaborados com a intenção de levar o aluno a memorizar e repetir lições, pouco ajudando na sua formação intelectual. Na prática, aprender era sinônimo de reproduzir. As poucas inovações metodológicas apresentadas pelos livros didáticos são os estudos dirigidos, cruzadinhas, palavrascruzadas e jogos rápidos, que pouco exigiam do aluno (ROCHA, 2008, p.132).

Dessa forma, a autora considera que além do conteúdo ideológico, os livros didáticos de História produzidos no contexto da Ditadura Civil-Militar contribuíram para a conformação de um ensino de História "tradicional", pautado na memorização dos conteúdos.

Segundo Gomes Neto et al (2014), tudo isso porque durante a Ditadura Militar o ensino de História sofreu grandes e preocupantes transformações. O Estado promoveu a descaracterização da História e da Geografia, que foram substituídas pelos Estudos Sociais com a intenção de esvaziar o conteúdo das Ciências Humanas.

A formação dos professores e os livros didáticos sofreram mudanças nesse contexto. Sendo que:

No que se refere a material didático das escolas da época, é possível perceber por meio da análise de obras de Estudos Sociais, o quanto é notável que o livro seguia à risca os conteúdos selecionados pelos autores, reproduzindo um modelo de história factual, uma história positivista que engrandecia grandes feitos, construindo ícones e heróis que deveriam ser lembrados, um ensino voltado para memorização e datas consideradas importantes (GOMES NETO et al., 2014, p. 3).

Outro conjunto de trabalhos analisa o conteúdo Ditadura Militar nos livros didáticos publicados durante e após o contexto da redemocratização. Munakata (1998), Rodeghero e Machado (2010), Reis e Prado (2012), Schröder e Masiero (2013), Silveira (2015), Almeida e Rodrigues Junior 
(2016) e Rocha (2017) identificaram nas pesquisas, problemas na produção didática recente sobre a Ditadura Militar. Esses problemas residem na manutenção de uma perspectiva tradicional a partir de acontecimentos cronológicos e factuais que excluem determinados setores da sociedade promovendo uma "história sem sujeitos" e ainda em uma "falsificação da História" no livro didático publicado pela Biblioteca do Exército - BIBLIEX.

Munakata (1998) em clássico artigo sobre os livros didáticos de História produzidos durante o contexto de redemocratização e a década de 1990, observa que essa literatura didática encampou o projeto de combater os "entulhos autoritários". Para tanto, os livros didáticos se apropriaram do referencial marxista organizando os conteúdos tradicionais a partir dos "modos de produção". O resultado acabou sendo uma História "economicista", que acabou silenciando os sujeitos.

Rodeghero e Machado (2010) tratam da temática da Lei da Anistia de 1979, preocupadas com a questão do protagonismo feminino, nos livros didáticos de História para o Ensino Médio. Os resultados indicam que é dada uma prevalência ao elemento masculino, porém com algumas inserções do movimento feminista pela anistia.

Reis e Prado (2012) analisaram o conteúdo Ditadura Militar nos livros História Integrada, História e Vida, História e Nova História Crítica. Como resultados, identificaram que nas quatro obras o conteúdo Ditadura Militar é tratado de maneira factual e linear sem contribuir para a problematização por parte dos professores e alunos.

Schröder e Masiero (2013) ao analisarem os livros História Integrada, Projeto Araribá e Encontros com a História inferiram que as temáticas da repressão, economia e a luta contra o regime são as que mais aparecessem nos livros, que consensualmente classificam o regime como autoritário e falam sobre o apoio da sociedade a ditadura.

Dessa forma, as pesquisadoras constataram que nesses livros mais recentes houve uma ampliação dos conteúdos relacionados a Ditadura Militar, sendo que: 
Possivelmente, esta gradativa ampliação de conteúdos relativos ao tema em questão, tenha se dado em virtude do trauma de tal período que ecoou por muitos anos e que aos poucos, ainda vem sendo desvelado, contribuindo para a compreensão das nuances do período. Esse acréscimo de informações talvez se deva, também, tanto ao surgimento de novas pesquisas que, aos poucos, vão servindo de base para a produção dos livros, quanto ao amadurecimento da democracia brasileira, aliada à também crescente criticidade e crítica da maioria da sociedade, para com a ditadura (SCHRÖDER; MASIERO, 2013, p. 18).

Silveira (2015) realizou uma análise do conteúdo Ditadura Militar no livro didático História Global: Brasil e Geral. Na análise constatou as inconstâncias entre a invisibilidade da sociedade civil na explicação do golpe militar e o protagonismo no fim do regime. Tal narrativa parece contribuir para uma memória "confortável" de que a sociedade civil não foi conivente com os crimes cometidos pelos agentes da Ditadura.

Almeida e Rodrigues Junior (2016) analisaram o livro didático História do Brasil: Império e República, publicado pela Biblioteca do Exército BIBLIEX e utilizado nas escolas militares. Essa obra tem a especificidade de não passar pelo processo de avaliação do PNLD, por conta da autonomia constitucional das Forças Armadas.

A narrativa histórica analisada não faz distinção entre memória e História e rejeita o conhecimento científico acumulado sobre o período. Dessa forma, em um movimento de "falsificação da História", o livro didático define o golpe militar como "Revolução", que resultou em um contexto de "democracia relativa", ignorando os documentos que evidenciam a repressão e a tortura no período.

Em trabalho recente, Helenice Rocha (2017) procura compreender a potencialidade das narrativas na constituição de sentidos acerca da Ditadura Militar no Brasil. Para isso analisou os textos principais ou textos base presentes nas coleções aprovadas pelo Programa Nacional do Livro Didático - PNLD em 2011.

Para situar o problema, a pesquisadora apresentou uma breve análise de obras publicadas entre 1969 e 1978, que tratam o período como 
"República Nova", "Deposição de João Goulart pelas Forças Armadas", "O movimento de 31 de março de 1964" ou ainda "Revolução Gloriosa", o que sinaliza as interdições determinadas pelo próprio regime.

Essas narrativas foram se transformando na década de 1980, quando começou-se a nomear o evento como golpe militar, mesmo que ainda de maneira tímida.

Todos os livros analisados são do 90 ano do Ensino Fundamental, sendo que dos 15 livros, 6 apresentaram a Ditadura em apenas um capítulo, 5 em capítulos encadeados e quatro integrados ou intercalados com a história mundial.

Sobre isso, Helenice Rocha (2017) observa que,

[...] a separação em capítulos diversos, bem como algumas vezes a forma alternada entre a história nacional e a história mundial - pode dificultar a compreensão do enredo, exigindo recapitulações e repetições, o que é realizado em parte nas narrativas das coleções, especialmente nas introduções dos capítulos (ROCHA, 2017, p. 252).

Ao tratar da construção da narrativa, a autora observa a existência de sujeitos individuais como Goulart e Lacerda e grupos de sujeitos coletivos. No entanto, "o potencial de produção de sentidos presente nessas narrativas sugere ao leitor principiante mais uma confusão do que uma polarização" (ROCHA, 2017, p. 254).

Ao contar a ditadura, os livros didáticos fundamentalmente dão protagonismo as Forças Armadas não considerando elementos como o conceito de "golpe civil-militar" indicados por uma nova historiografia do período.

Ainda sobre isso, as coleções silenciam em relação aos consentimentos sociais às ações da chamada "linha dura", a partir do uso de denominações genéricas como "anos de chumbo" e "porões da ditadura", que tornam impessoal os atos de violência praticados no período. 
Já no desfecho há um fortalecimento da sociedade civil como "protagonista" da História e uma descontinuidade entre os personagens civis e militares, que prejudica a compreensão.

Dessa maneira,

Ao analisar o tratamento do tema da ditadura militar no Brasil nas narrativas de livros didáticos de história do Ensino Fundamental, é possível concluir que elas atendem à finalidade social de apresentação de uma história compreensível às novas gerações, porém com algumas lacunas e incongruências relativas a mecanismos internos e externos ao texto (ROCHA, 2017, p. 263).

A narrativa escolar vinculada pelos livros analisados parece padecer dos constrangimentos próprios da temporalidade em que ela foi escrita, a partir de outras escritas com o mesmo efeito. Assim, parece ainda muito impactada pela memória ao aliviar discursivamente quando trata dos consentimentos da sociedade civil aos crimes cometidos naquele contexto histórico atribuindo protagonismo quase exclusivo aos militares durante a maior parte do contexto histórico.

Esse segundo conjunto de pesquisas, em menor ou maior grau, permite evidenciar as mudanças promovidas nos livros didáticos recentes que passaram a tratar de maneira ampliada do tema Ditadura Militar. Apesar disso, persiste o problema de uma "história sem sujeitos", na medida que a maioria das obras apresenta uma narrativa excessivamente centrada nos personagens políticos do contexto. Cabe destacar a excepcionalidade do livro didático publicado pela BIBLIEX, que produz uma contranarrativa que ignora a historiografia sobre o tema.

\section{Os livros didáticos analisados}

O Programa Nacional do Livro Didático - PNLD foi criado por meio do Decreto no 91.542/1985. De lá para cá, foi transformado em política de Estado e um dos maiores programas de avaliação, aquisição e distribuição de livros didáticos do mundo. Neste artigo, consideramos os livros didáticos aprovados pelo edital do PNLD 2017 destinado os anos finais do Ensino 
Fundamental. Foram aprovadas 14 coleções de livros didáticos de História direcionados a esse nível de ensino. Dentre elas, selecionamos para análise as três coleções mais escolhidas pelos professores: História, Sociedade \& Cidadania (2015), Araribá - História (2015) e Vontade de Saber (2015).

A coleção História, Sociedade \& Cidadania, de autoria de Alfredo Boulos Junior foi publicada pela FTD em 2015. As unidades temáticas e os capítulos iniciam-se com páginas que contêm fontes históricas e um parágrafo com questões que buscam problematizar os conhecimentos prévios dos alunos, relacionando-os ao foco da unidade. Além do texto principal, há seções não fixas: Para Refletir; Retomando; Leitura de Imagem; Leitura e Escrita de Textos; Cruzando Fontes; Integrando; Você Cidadão e o boxe Para Saber Mais.

Figura 1 - Capa do livro didático do $9^{\circ}$ ano da coleção História, Sociedade \& Cidadania (2015)

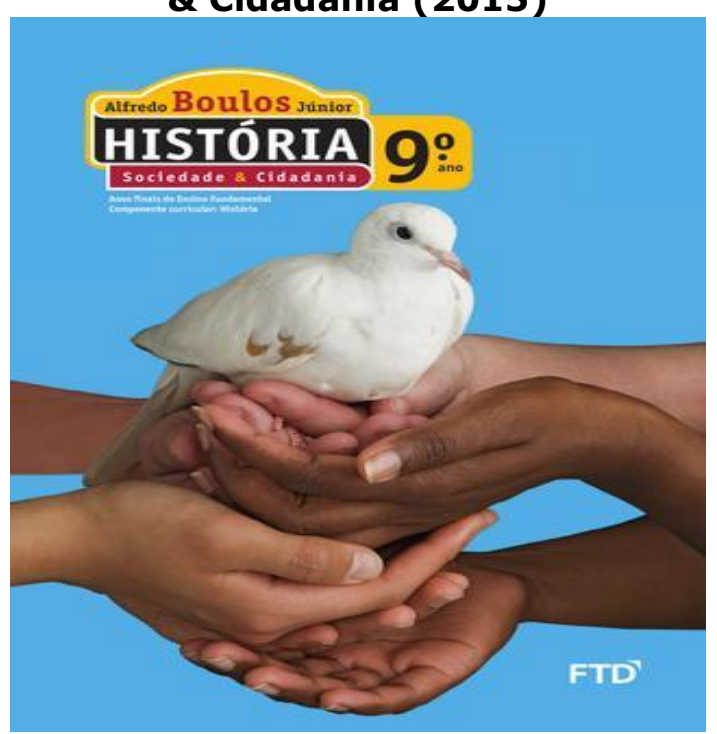

Fonte: Boulos Junior (2015).

O livro didático da coleção Araribá - História publicado pela editora Moderna em 2015 e organizado pela editora Maria Raquel Apolinário dividese em nove unidades, subdivididas entre quatro ou cinco temas. Os volumes possuem seções como: Apresentação; Página de Abertura; De Olho no Infográfico, com informações complementares, imagens e questões 
sobre o tema; A sessão Em Foco é composta por texto e trechos de fontes acompanhados de exercícios e sugestões de trabalho.

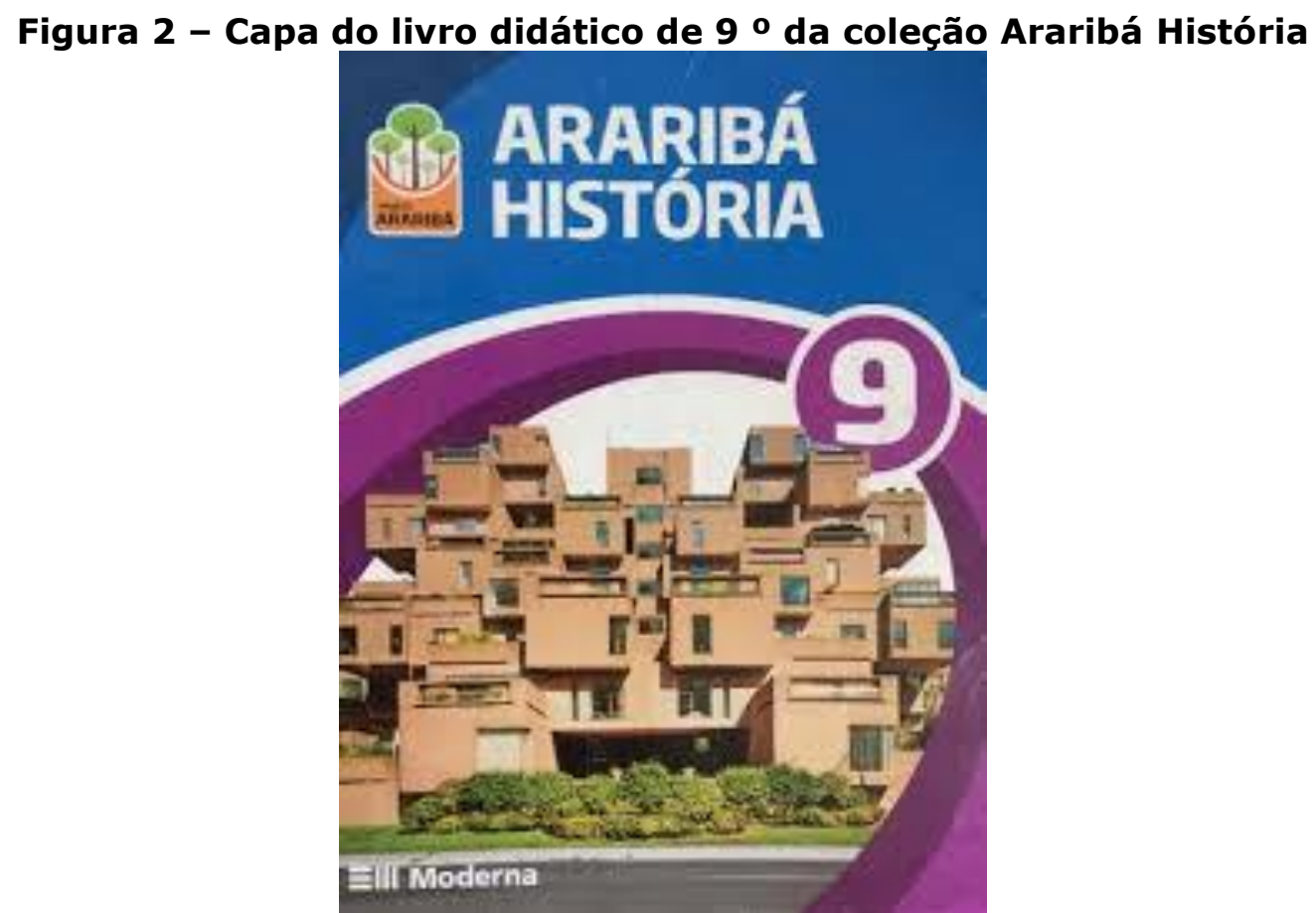

Fonte: Apolinário (2015)

A coleção Vontade de Saber, também publicada pela FTD em 2015, de autoria de Adriana Dias, Keila Grinberg e Marco Pellegrini se divide em nove capítulos, compostos por texto-base e seções. Todos os volumes possuem uma apresentação e nove seções que não são, necessariamente, fixas: Abertura do capítulo; O sujeito na história; História em construção; explorando a imagem; explorando o tema; Encontro com; enquanto isso; investigando na prática e Atividades. As duas páginas iniciais de cada capítulo apresentam imagens referentes ao conteúdo a ser trabalhado, buscando atentar para o conhecimento prévio dos alunos. As quatro últimas páginas são reservadas para as atividades. 


\section{Figura 3 - Capa do livro didático do $9^{\circ}$ ano da coleção Vontade de Saber História}



Fonte: Dias; Grinberg; Pellegrini (2015)

Selecionadas as coleções didáticas passamos a analisar o conteúdo com o objetivo de identificar em qual série o conteúdo histórico Ditadura Militar estava presente. Dessa forma, observamos que nas três coleções essa temática está alocada nos livros do $9^{\circ}$ ano do Ensino Fundamental.

Na sequência selecionamos os capítulos/unidade de análise que tratam deste conteúdo histórico:

Quadro 1 - Capítulos/unidades que tratam da Ditadura Civil-Militar nos livros didáticos selecionados

\begin{tabular}{|c|c|c|}
\hline Coleção & Capítulo/Unidade & Páginas \\
\hline História, Sociedade \& Cidadania & 13. Regime Militar & $225-251$ \\
\hline Araribá - História & $\begin{array}{c}\text { 11. A ditadura militar no } \\
\text { Brasil }\end{array}$ & $265-295$ \\
\hline Vontade de Saber - História & 7. Democracia e ditadura & $209-221$ \\
\hline
\end{tabular}


na América Latina

Fonte: Os autores (2018).

\section{As narrativas históricas sobre a Ditadura Civil-Militar nos livros didáticos de História aprovados pelo PNLD 2017}

Partindo dos critérios propostos por Rüsen (2010) passamos a análise dos capítulos/unidades que tratam da temática Ditadura Militar no Brasil.

Inicialmente procuramos identificar nos livros se havia textos historiográficos. Não identificamos nos livros didáticos História, Sociedade \& Cidadania (2015) e Araribá - História (2015), a presença desses textos. Encontramos no livro Vontade de Saber, um trecho de um texto da historiadora Sandra Maria Castanho, intitulado Tortura: uma estratégia para coibir os adversários do regime militar. Contudo, de acordo com Rüsen (2010), os textos historiográficos devem estar claramente diferenciados da documentação e da narrativa histórica dos autores dos livros didáticos e não apenas ilustrar os conteúdos apresentados. Nesse caso, o texto historiográfico se confunde com a narrativa e acaba por ilustrar as ideias dos autores.

Outro critério proposto por Rüsen (2010), a pluriperspectividade aos níveis dos afetados e do observador, é necessária para que a experiência histórica seja apresentada também a partir da perspectiva dos afetados por aquele evento histórico, sem desconsiderar a existência de múltiplas perspectivas sobre um mesmo evento histórico. Ao nível dos afetados, no livro História, Sociedade \& Cidadania (2015) o autor utiliza a música Disparada, composta por Geraldo Vandré, para demonstrar a visão do afetado diante do regime militar. Nesse caso, um artista atingido pela censura. No Araribá - História (2015), identificamos a sessão Memórias do Porão, que apresenta o relato de Hamilton Pereira, presidente de uma entidade estudantil que foi vítima de tortura durante a Ditadura. No caso da coleção Vontade de Saber os afetados são representados por Tarso de Castro, um dos fundadores do jornal $O$ pasquim.

História \& Ensino, Londrina, v. 25, n. 02, p. 217-237, jul./dez. 2019 
Com relação a pluriperspectividade ao nível do observador não identificamos a presença de diferentes perspectivas historiográficas sobre o evento histórico. Identificamos, na grande maioria das vezes a presença de narrativas, que por mais que trabalhem com diferentes dimensões do evento histórico, não explicitam essa multiperspectividade historiográfica.

No que tange as normas cientificas, é possível perceber que todos os livros seguem a tese de que o golpe foi um "golpe-civil-militar". No livro Vontade de saber (2015), ao tratar da implantação da Ditadura Militar, o livro descreve o apoio de uma parcela da população civil. Pudemos observar nos três livros didáticos, que o golpe já não foi abordado como um movimento protagonizado pelas Forças Armadas, diferença significativa em relação aos livros didáticos do PNLD 2011 analisados por Helenice Rocha (2017). Essa participação é ressaltada no seguinte trecho:

Após o golpe, a cúpula das Forças Armadas assumiu as funções de governo, contando com o auxilio de uma parcela da população civil, com a qual dividiu parte do poder e dos privilégios (DIAS; GRINBERG; PELLEGRINI; 2015, p. 270).

No livro História, Sociedade \& Cidadania (2015), esses setores da população já são mais definidos, como é percebido no seguinte trecho:

Com o apoio de uma parte a sociedade brasileira, formada por latifundiários, grandes industriais e banqueiros, além de parte da classe média. Esses grupos sentiam-se ameaçados pelos "agentes de Moscou", supostos comunistas que pretendiam transformar o Brasil em um país socialista (BOULOS JÚNIOR, 2015, p. 227).

No livro Araribá - História (2015), um dos principais fatores tidos para a deposição de Jango é o fato de o enxergarem como uma ameaça comunista. Enquanto, na obra Vontade de saber (2015) os autores também se utilizam do mesmo termo dizendo que "a justificativa dos golpistas era a necessidade de garantir a ordem interna no país" (DIAS; GRINBERG;PELEGRINI, 2015, p. 270). 
Em uma passagem da obra Araribá - História (2015, a abordagem dos movimentos de resistência é vaga. O livro trata da resistência apenas a partir de movimentos como a passeata dos $100 \mathrm{mil}$ e, mais à frente, o movimento de organização e sindicalização nas regiões do $A B C$.

Percebe-se a ausência de uma dimensão diacrônica, onde o aluno possa perceber a atuação desses movimentos em diversos momentos da Ditadura Militar. Além disso, o movimento estudantil poderia ter sido abordado de maneira mais ampla, já que sua atuação esteve presente em quase todos os movimentos de resistência democrática.

Voltando ao livro Vontade de Saber (2015), os autores constroem uma linha do tempo com alguns fatos ocorridos durante a Ditadura Militar, destacando os principais acontecimentos no governo de cada presidente. A linha do tempo inicia-se com o Golpe em 1964 e termina com a posse de José Sarney, que o texto apresenta como "fato que marca o fim do regime militar". Os atos institucionais são abordados em sequência, dando destaque para o AI-2, ato que extinguia todos os partidos e instaurava o bipartidarismo e ao AI-5, porém, de forma superficial.

Porém a visão diacrônica, ou seja, os efeitos desses atos institucionais não são claramente percebidos ao longo da narrativa.

Logo depois de tratar do mais duro ato do período militar, o livro trata da Doutrina de Segurança Nacional como "base ideológica da política autoritária", em seguida, faz uma relação dessa doutrina com as perseguições, prisões e exílios, dos "porões" da ditadura e da censura. A ideia de "porões" da ditadura ao referir-se as práticas de tortura e repressão não oficializadas muitas vezes pode ser entendida pelo aluno como um total desconhecimento por parte da sociedade sobre essas práticas, conforme observa Rocha (2017).

O livro Vontade de Saber (2015) apresenta ainda um tópico intitulado $A$ arte engajada em que os autores tratam da resistência cultural no cinema, no teatro, na música, dando destaque as canções de protesto, ao movimento do tropicalismo e ao rock nacional. Esse tópico poderia ser 
relacionado com o AI-5, que teve impacto decisivo nessas manifestações artísticas.

Em um trecho do Araribá - História (2015), também se tem uma seção destinada a tratar da cultura, porém, essa seção é apresentada depois do capítulo sobre a redemocratização e a constituição de 1988. A maneira como foi dividido o tema não permite que o aluno possa relacionar e construir sentido de forma efetiva.

Dessa forma, com relação a pluralidade da experiência histórica identificamos o ponto de vista sincrônico proposto por Rüsen (2010), quando os autores tratam da cultura. No entanto, observamos ainda a prevalência do âmbito político da experiência. Um exemplo pode ser identificado no livro didático História, Sociedade \& Cidadania (2015), que divide o capítulo analisado em 8 subitens, sendo 6 intitulados Governo de, seguido pelo nome do presidente.

A perspectiva diacrônica, entendida como "nível temporal de mudanças em longo prazo no nível das estruturas de ação, por um lado, e mudanças de curto prazo ao nível dos acontecimentos, por outro" (RÜSEN, 2010, p. 121) acaba negligenciado pelos autores. As narrativas não permitem observar o caráter processual da História e acabam por descrever eventos históricos que parecem petrificados no passado.

Para além dos critérios identificamos que na grande maioria dos casos, os autores apresentam narrativas históricas tradicionais, que "[...] articula as tradições como condições necessárias para os seres humanos encontrarem seu caminho" (RÜSEN, 2010, p. 99).

No livro didático Vontade de Saber (2015) os autores ao tratarem do AI5 observam que,

O AI-5 foi uma das medidas mais duras do período e concedeu plenos poderes ao presidente, que fechou 0 Congresso Nacional, as Assembleias Nacionais e as Câmaras de Vereadores. Além disso, o presidente podia cassar mandatos e nomear interventores. (DIAS; GRINBERG; PELLEGRINI, 2015, p. 272). 
Nesse exemplo observamos a construção de uma tipologia narrativa, que meramente descreve o conteúdo e os resultados do Ato Institucional No 5, sem produzir uma crítica, exemplos ou relações com o presente.

Na obra Araribá - História (2015) os autores observam sobre o movimento estudantil que,

Dois momentos marcaram a atuação do movimento estudantil: a invasão da PUC pela polícia em 1977 e a participação dos estudantes nas greves dos trabalhadores do ABC em 1978 (APOLINÁRIO, 2015, p. 217).

Nesse caso, os autores utilizam dois eventos para construir uma espécie de genealogia do movimento estudantil, elemento característico das narrativas históricas tradicionais.

Ao tratar do golpe militar, Boulos Junior (2015) afirma que,

Dizendo que era necessário livrar o país da ameaça comunista e reestabelecer a hierarquia, um grupo formado por civis e militares derrubou João Goulart e tomou o poder. $O$ regime estabelecido por eles durou 21 anos e pode ser chamado de Regime Militar (1964-1985) (BOULOS JUNIOR, 2015, p. 226).

Neste fragmento novamente observamos o sentido genealógico ao explicar a origem e delimitar temporalmente o Regime Militar.

\section{Algumas considerações}

As análises dos três livros didáticos aprovados pelo PNLD 2017 nos permitiram considerar alguns resultados, mas também construir hipóteses acerca das narrativas históricas sobre a Ditadura Militar nos livros didáticos de História.

No campo dos resultados, identificamos uma ampliação da temática organizada em capítulos/unidades específicos com espaço de aproximadamente 30 páginas nos livros didáticos de História para o 90 ano do Ensino Fundamental.

História \& Ensino, Londrina, v. 25, n. 02, p. 217-237, jul./dez. 2019 
Com relação aos critérios indicados por Rüsen (2010) identificamos apenas um texto historiográfico no livro didático Araribá - História (2015), utilizado para ilustrar o conteúdo histórico das narrativas dos autores.

Observamos certa preocupação com a pluriperspectividade ao nível dos afetados presente nas produções artísticas, na história de vida e mesmo nos relatos de tortura daqueles que vivenciaram e sofreram as agruras do período.

E também inferimos certa renovação historiográfica observada no uso do conceito de Ditadura Civil-Militar, caro a historiografia brasileira contemporânea, a partir da obra de Daniel Aarão Reis (2014). Esse elemento nos permite indicar de maneira tímida, que houve avanços na produção didática acerca da Ditadura Militar de 2011 para 2017, com base na pesquisa realizada por Rocha (2017).

Contudo, os livros didáticos carecem de pluriperspectividade ao nível do observador, ao não se preocupar em apresentar as diferentes perspectivas historiográficas acerca do evento histórico, e também de pluralidade da experiência ao ainda darem relevância primordial a uma história política centrada nos personagens "importantes".

Como hipóteses consideramos, conforme Rüsen (2010) a necessidade de realizarmos investigações sobre os usos dos livros didáticos com o intuito de compreender de que forma as ideias históricas presentes nessas publicações didáticas impactam na consciência histórica dos estudantes.

Dessa forma, de maneira geral, por mais que tenham progredido em alguns aspectos, os livros didáticos analisados mantêm uma narrativa histórica tradicional centrada nos elementos políticos, que acaba produzindo uma história "sem sujeitos", ainda protagonizada pelos militares, e por grupos homogêneos como "classe média". Assim, a Ditadura Militar parece continuar sendo narrada não para provocar repulsa e fortalecimento da democracia, mas para contribuir a compreensão da história política do Brasil.

\section{Referências}

História \& Ensino, Londrina, v. 25, n. 02, p. 217-237, jul./dez. 2019 
Almeida, Sabrina Basílio de; RODRIGUES JUNIOR, Osvaldo Rodrigues. $A$ falsificação da história no livro didático História do Brasil: Império e República. In: Mnemosine revista, volume 7, no 4, out/dez 2016, p. 221234.

APOLINÁRIO, Maria Raquel (ed.). Araribá: história: 90 ano. São Paulo: Moderna, 2015.

BOULOS JUNIOR, Alfredo. História, Sociedade \& Cidadania: $9^{\circ}$ ano. São Paulo: FTD, 2015.

DIAS, Adriana; GRINBERG, Keila; PELLEGRINI, Marco. Vontade de Saber: história: 90 ano. São Paulo: FTD, 2015.

FICO, Carlos. Versões e controvérsias sobre 1964 e a ditadura militar. Revista Brasileira de História, São Paulo, v. 24, n. 47, p. 29-60, 2004.

FICO, Carlos. Ditadura militar brasileira: aproximações teóricas e historiográficas. Revista Tempo e Argumento, Florianópolis, v. 9, n. 20, p. 5-74, jan./abr. 2017.

FICO, Carlos. História do Brasil contemporâneo. São Paulo: Contexto, 2015.

MUNAKATA, Kazumi. História que os livros didáticos contam, depois que acabou a ditadura. In: FREITAS, Marcos Cezar (org.). Historiografia brasileira em perspectiva. São Paulo: Contexto, 1998. p. 271-290.

GASPARI, Elio. A ditadura derrotada. São Paulo: Cia das Letras, 2003. (As ilusões armadas, v. 3).

GOMES NETO, Manoel; PATRÍCIO, Viviane Edna Vieira; AQUINO, Viviane de Fátima; SOUZA, Wellerson Almeida de. A ditadura militar e o ensino de história: livro didático durante e depois do golpe de 1964. In: ENCONTRO DE INICIAÇÃO À DOCÊNCIA DA UNIVERSIDADE ESTADUAL DA PARAÍBA, 4. 2014, João Pessoa. Anais [...]. João Pessoa: UEPB, 2014.

REIS, Tiago Felipe; PRADO, Eliane Mimese. A ditadura militar brasileira em determinados manuais didáticos da educação básica. Revista Intersaberes, [São Paulo], v. 7, n. 14, p. 278-290, ago./dez. 2012.

REIS, Daniel Aarão. Ditadura e democracia no Brasil: do golpe de 1964 à Constituição de 1988. Rio de Janeiro: Zahar, 2014.

ROCHA, Aristeu Castilhos. O regime militar no livro didático de história do ensino médio: a construção de uma memória. 2008. Tese (Doutorado em História) - Pontifícia Universidade Católica do Rio Grande do Sul, Porto Alegre, 2008.

História \& Ensino, Londrina, v. 25, n. 02, p. 217-237, jul./dez. 2019 
ROCHA, Helenice. A ditadura militar nas narrativas didáticas. In: ROCHA, Helenice; REZNIK, Luis; MAGALHÃES, Marcelo de Souza (org.). Livros didáticos de história: entre políticas e narrativas. Rio de Janeiro: FGV Editora, 2017. p. 245-263.

RODEGHERO, Carla Simone; MACHADO, Vanderlei. A história recente nos livros didáticos: a ditadura militar e a questão da anistia no Brasil. Cadernos do Aplicação, Porto Alegre, v. 23, n. 1, p. 165-195, jan./jun. 2010

RÜSEN, Jörn. Jörn Rüsen e o ensino de História. Curitiba: Editora da UFPR, 2010.

SCHRÖDER, Janice Roberta; MASIERO, Claudia Gisele. Livros didáticos e abordagens sobre o período de ditadura civil-militar no Brasil. In: SEMINÁRIO DE ESTUDOS HISTÓRICOS, 11., 2013, Novo Hamburgo. Anais [...]. Novo Hamburgo: Feevale, 2013. p. 1-19.

SILVEIRA, Danielle Rodrigues. História do tempo presente e livro didático: os sujeitos da Ditadura Militar nos livros didáticos de História. In: SIMPÓSIO NACIONAL DE HISTÓRIA, 28., 2015, Florianópolis. Anais [...]. Florianópolis: UFSC, 2015. p. 2 -11. 